\section{(2) \\ BRAZIULIAN JOURNAL \\ OF MEDICAL AND BIOLOGICAL RESEARCH}

www.bjournal.com.br
ISSN 0100-879X

Volume 45 (3) 179-290 March 2012

BIOMIEDICAL SCIENCES

AND

CLINICAL INVESTIGATION

Braz J Med Biol Res, March 2012, Volume 45(3) 205-211

doi: 10.1590/S0100-879X2012007500019

Effect of trimetazidine treatment on the transient outward

potassium current of the left ventricular myocytes of rats with

streptozotocin-induced type 1 diabetes mellitus

Yu-luan Xiang, Li He, Jun Xiao, Shuang Xia, Song-bai Deng, Yun Xiu and Qiang She

The Brazilian Journal of Medical and Biological Research is partially financed by

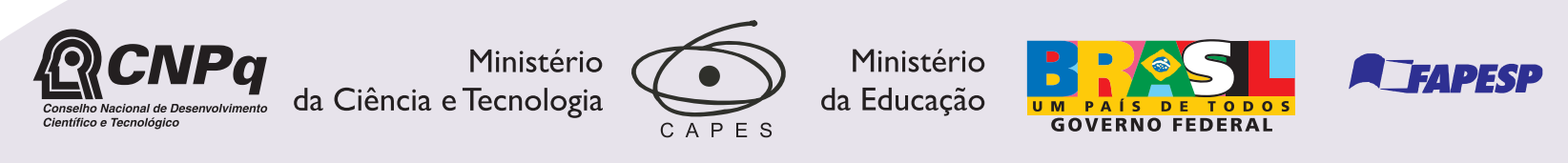

Institutional Sponsors

songo
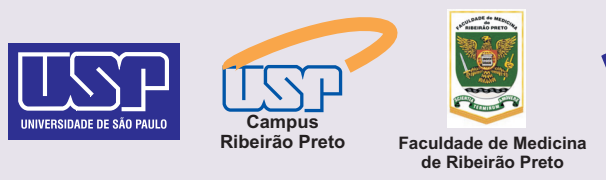

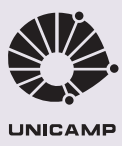

SHIMADZU

Associaçăo
Fundo de Incentivo
à Pesquisa

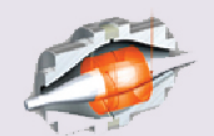

UNICAMP

lore High - Performance MS Orbitrap Technology analitica Thermo 


\title{
Effect of trimetazidine treatment on the transient outward potassium current of the left ventricular myocytes of rats with streptozotocin-induced type 1 diabetes mellitus
}

\author{
Yu-luan Xiang ${ }^{1}$, Li He ${ }^{1}$, Jun Xiao², Shuang Xia ${ }^{1}$, Song-bai Deng ${ }^{1}$, \\ Yun $\mathrm{Xiu}^{3}$ and Qiang She ${ }^{1}$
}

1Department of Cardiology, the Second Affiliated Hospital, Chongqing Medical University, Chongqing, China 2Department of Cardiology, Chongqing Emergency Medical Center, Chongqing, China

${ }^{3}$ Institute of Life Science, Chongqing Medical University, Chongqing, China

\begin{abstract}
Cardiovascular complications are a leading cause of mortality in patients with diabetes mellitus (DM). The present study was designed to investigate the effects of trimetazidine (TMZ), an anti-angina drug, on transient outward potassium current ( to $\left._{\text {o }}\right)$ remodeling in ventricular myocytes and the plasma contents of free fatty acid (FFA) and glucose in DM. Sprague-Dawley rats, 8 weeks old and weighing 200-250 g, were randomly divided into three groups of 20 animals each. The control group was injected with vehicle (1 $\mathrm{mM}$ citrate buffer), the DM group was injected with $65 \mathrm{mg} / \mathrm{kg}$ streptozotocin (STZ) for induction of type $1 \mathrm{DM}$, and the DM+TMZ group was injected with the same dose of STZ followed by a 4-week treatment with TMZ $\left(60 \mathrm{mg} \cdot \mathrm{kg}^{-1} \cdot \mathrm{day}^{-1}\right)$. All animals were then euthanized and their hearts excised and subjected to electrophysiological measurements or gene expression analyses. TMZ exposure significantly reversed the increased plasma FFA level in diabetic rats, but failed to change the plasma glucose level. The amplitude of $l_{\text {to }}$ was significantly decreased in left ventricular myocytes from diabetic rats relative to control animals $(6.25 \pm 1.45 \mathrm{vs} 20.72 \pm 2.93 \mathrm{pA} / \mathrm{pF}$ at $+40 \mathrm{mV})$. The DM-associated $I_{\text {to }}$ reduction was attenuated by TMZ. Moreover, TMZ treatment reversed the increased expression of the channel-forming alpha subunit Kv1.4 and the decreased expression of Kv4.2 and Kv4.3 in diabetic rat hearts. These data demonstrate that TMZ can normalize, or partially normalize, the increased plasma FFA content, the reduced $I_{\text {to }}$ of ventricular myocytes, and the altered expression $\mathrm{Kv} 1.4, \mathrm{Kv} 4.2$, and Kv4.3 in type $1 \mathrm{DM}$
\end{abstract}

Key words: Transient outward $\mathrm{K}^{+}$current; Free fatty acid; Trimetazidine; Diabetic cardiomyopathy; Channel protein; Ventricular myocytes

\section{Introduction}

Diabetes mellitus (DM) has become one of the most common chronic diseases worldwide. It is predicted that the global number of affected people will double between 2000 and 2030, increasing from 171 million to 366 million (1). There are two main types of DM: type $1 \mathrm{DM}$ and type 2 DM. Type 1 results from the loss of insulin production in the beta cells of the pancreas, while type 2 results from a lack of serum insulin or poor uptake of glucose into the cells. Cardiovascular complications are the leading cause of death in the diabetic population. The incidence of cardiovascular disease is increased in individuals with DM compared to those without DM. Hyperglycemia, dyslipidemia, and inflammation have been proposed to account for the prevalence of cardiovascular disease in diabetic subjects (2). In addition to vascular disorders $(3,4)$, patients with DM are predisposed to myocardial dysfunction (5,6). Diabetic cardiomyopathy is associated with abnormal electrical remodeling (7-9) and myocardial structure alterations $(10,11)$. The prolongation of the QT interval is the most prominent electrocardiographic change in diabetic hearts; clinically, its prevalence is as high as about $25 \%$ in diabetic subjects $(12,13)$. QT prolongation is an important predictor of mortality in patients with

Correspondence: Qiang She, Department of Cardiology, the Second Affiliated Hospital, Chongqing Medical University, 76 Linjiang Road, Chongqing 400010, China. Fax: +86-23-6384-7209. E-mail: qshe98@hotmail.com

Received July 3, 2011. Accepted February 6, 2012. Available online February 17, 2012. Published March 19, 2012. 
DM because it is associated with increased propensity to sudden cardiac death consequent to malignant ventricular arrhythmias.

The transient outward potassium $\left(\mathrm{K}^{+}\right)$current $\left(I_{\text {to }}\right)$ is a major current in the heart, which is responsible for phase 1 repolarization of the cardiac action potential (14). Two functionally distinct $I_{\text {to }}$ phenotypes exist in the myocardium: rapidly recovering $\left(I_{\text {to, }}\right)$ and slowly recovering $\left(I_{\text {to, }}\right)$. Molecularly, cardiac $l_{\text {to }}$ is generated by the voltage-gated $(\mathrm{Kv})$, pore-forming (alpha) subunits, Kv4.2, Kv4.3, and Kv1.4. While Kv1.4 is responsible for $I_{\text {to,s }}$ channels, both Kv4.2 and $\mathrm{Kv} 4.3$ contribute to $I_{\text {to, }}$ channels (15). Down-regulation of $I_{\text {to }}$ is a consistent finding in diabetic hearts (16-18). However, at present, the mechanism(s) by which DM influences the density of cardiac $I_{\text {to }}$ is not completely understood. Li et al. (19) reported that $I_{\text {to }}$ remodeling in the diabetic rat heart is controlled by endogenous oxidoreductase systems in a redox-sensitive manner. Xu et al. (16) provided evidence that there is a metabolic basis for decreased $I_{\text {to }}$ density in ventricular myocytes from diabetic rats. Indeed, amphiphilic fatty acid metabolites (e.g., palmitoylcarnitine and palmitoyl-coenzyme A) are able to inhibit the $I_{\text {to }}$ density in rat ventricular myocytes (20).

There is a consensus that DM alters cardiac substrate metabolism $(21,22)$, resulting in a switch from glucose oxidation to free fatty acid (FFA) oxidation. The preferential utilization of FFA in diabetic hearts causes not only a reduced energy production, but also an increase of intermediate metabolic products that are toxic to the myocardium (23). Trimetazidine (TMZ) belongs to a new class of metabolic agents known as the 3-ketoacyl coenzyme A thiolase (3-KAT) inhibitors. TMZ has the capacity to shift cardiac energy metabolism from FFA oxidation to glucose oxidation by inhibiting mitochondrial long-chain 3-KAT and thus improving cardiac efficiency $(24,25)$. A double-blind placebo-controlled study conducted by Rosano et al. (26) revealed that $T M Z$ can improve left ventricular function in diabetic patients with coronary artery disease. However, few studies have described the effects of TMZ on cardiac electrical remodeling and energy metabolism in the setting of DM. In the present study, we used a rat model of type $1 \mathrm{DM}$ and examined the influence of TMZ treatment on $I_{\text {to }}$ density in ventricular myocytes, the expression of $\mathrm{Kv}$ channel genes, as well as the plasma FFA and glucose levels.

\section{Material and Methods}

\section{Experimental solutions}

Tyrode solution, $\mathrm{pH} 7.4$, containing $135 \mathrm{mM} \mathrm{NaCl}, 5.4$ $\mathrm{mM} \mathrm{KCl}, 1 \mathrm{mM} \mathrm{MgCl}_{2}, 0.33 \mathrm{mM} \mathrm{NaH}_{2} \mathrm{PO}_{4}, 10 \mathrm{mM}$ HEPES, and $10 \mathrm{mM}$ glucose was used and Kraft Brühe (KB) solution, $\mathrm{pH} 7.4$, containing $85 \mathrm{mM} \mathrm{KOH}, 30 \mathrm{mM} \mathrm{KCl}, 30 \mathrm{mM} \mathrm{KH}_{2} \mathrm{PO}_{4}$, $1 \mathrm{mM} \mathrm{MgCl}_{2}, 50 \mathrm{mM}$ glutamic acid, $20 \mathrm{mM}$ taurine, $0.5 \mathrm{mM}$ EGTA, $10 \mathrm{mM}$ HEPES, and $10 \mathrm{mM}$ glucose was used. The pipette solution, $\mathrm{pH} 7.2$, containing $140 \mathrm{mM} \mathrm{KCl}, 1 \mathrm{mM}$ $\mathrm{MgCl}_{2}, 5 \mathrm{mM} \mathrm{KH}_{2} \mathrm{PO}_{4}, 5 \mathrm{mM}$ EGTA, and $10 \mathrm{mM}$ HEPES and the external solution, $\mathrm{pH} 7.4$, containing $140 \mathrm{mM} \mathrm{NaCl}$, $4 \mathrm{mM} \mathrm{KCl}, 1.5 \mathrm{mM} \mathrm{CaCl}_{2}, 1 \mathrm{mM} \mathrm{MgCl}_{2}, 0.5 \mathrm{mM} \mathrm{CdCl}_{2}, 5$ $\mathrm{mM}$ HEPES, and $10 \mathrm{mM}$ glucose were used.

\section{Animals and treatments}

The protocol of this study was approved by the Animal Care and Use Committee of Chongqing Medical University (Chongqing, China), with certification No. CMU-2010-0029. All experiments involving animals were carried out according to the EC Directive 86/609/ECC for animal care. SpragueDawley rats, 8 weeks old and weighing 200-250 g, were supplied by the Experimental Animal Center of Chongqing Medical University. They were randomly divided into three groups of 20 animals each: control group, DM group, and $\mathrm{DM}+\mathrm{TMZ}$ group. Streptozotocin (STZ) was used to induce experimental type 1 DM (16). Animals in both DM and $\mathrm{DM}+\mathrm{TMZ}$ groups were injected with a single dose of STZ (65 mg/kg, ip; Sigma, USA). Control animals were injected with the same dose of vehicle (1 mM citrate buffer, $\mathrm{pH} 4.5$ ). Blood glucose measurements were made 3 days after injection and daily thereafter to monitor the diabetic state. Rats whose plasma glucose level exceeded $16.7 \mathrm{mM}$ were considered diabetic. For a period of 4 weeks, animals in the $\mathrm{DM}+\mathrm{TMZ}$ group received TMZ $\left(60 \mathrm{mg} \cdot \mathrm{kg}^{-1} \cdot \mathrm{day}^{-1}\right.$; Servier Co., Ltd., China) by gavage. The other two groups received the same volume of normal saline. All animals were then euthanized by infusion of pentobarbital sodium (60 mg/kg, ip). Hearts from half the animals in each group were subjected to electrophysiological measurements and those from the other half were used for gene expression analysis.

\section{Preparation of cardiac myocytes}

Rat myocytes were isolated as described in Ref. 27. Briefly, freshly excised rat hearts were mounted on a Langendorff apparatus and perfused with Tyrode solution containing type II collagenase (Worthington, Freehold, USA) and $20 \mu \mathrm{M} \mathrm{CaCl}_{2}$ for 10-13 min. The ventricles of the heart were excised and minced lightly in KB solution. After filtering through a 200- $\mu$ m nylon mesh, disassociated cells were washed gently and centrifuged at $400 \mathrm{~g}$ for $5 \mathrm{~min}$. The cell suspension in fresh $\mathrm{KB}$ solution was kept at $4^{\circ} \mathrm{C}$ until electrophysiological studies were performed.

\section{Whole-cell patch-clamp technique}

The patch-clamp experiments were performed as described previously (28), with minor modifications. Briefly, ventricular cells were placed in a small-volume recording chamber under an inverted microscope. Cells were treated with the $I_{\text {to }}$ external solution for 15 min before recording the current. Patch electrodes were fabricated from borosilicate glass. The pipettes had a resistance of 2-4 $\mathrm{M} \Omega$ after filling with the internal solution. Creation of a voltage-clamp pulse and data acquisition were carried out using the 
Pulse software (version 8.31; HEKA, Germany). Whole cell capacitance was compensated. Series resistance in whole-cell recordings was $<20 \mathrm{M} \Omega$ and was not corrected. Aliquid junction potential was subtracted from the recorded membrane potentials. Current and voltage signals were filtered at $2.9 \mathrm{kHz}$ using a four-pole low-pass Bessel filter. Currents were sampled with the help of an analog-to-digital converter (HEKA). Ito was evoked by $300-\mathrm{ms}$ depolarizing pulses between -40 and $+70 \mathrm{mV}$. The holding potential was $-70 \mathrm{mV}$, and a 25-ms pre-pulse was applied to -30 $\mathrm{mV}$ to inactivate the fast sodium $\left(\mathrm{Na}^{+}\right)$current. At each test potential, the amplitude of $I_{\text {to }}$ was measured as the difference between peak outward current and current at the end of the test pulse. Current-voltage $(I-V)$ data were recorded by changing the test potential from -40 to $+70 \mathrm{mV}$ at 5-mV steps. By dividing the measured current amplitude by membrane capacitance $(\mathrm{Cm})(\mathrm{pA} / \mathrm{pF})$, I $_{\text {to }}$ currents were reported as current densities.

\section{Quantitative real-time polymerase chain reaction (qRT-PCR)}

Total RNA from rat myocardium was extracted using Trizol reagent according to manufacturer instructions (Invitrogen, USA). Reverse transcription was performed with random primers (Invitrogen) and M-MLV reverse transcriptase (Invitrogen). Real-time PCR amplification was conducted on the Applied Biosystems 7500 Real-Time PCR System (USA) using SYBR Green PCR Master Mix (Life Technologies Corporation, USA). The PCR primers were as follows: forward 5'-GCAGTCAGTTGCCCATACC-3' and reverse 5'-TCCCTTTCCCTGACACTTC-3' for Kv1.4 (152 bp in length; Genbank No. NM_012971); forward 5'-CTCTCTG AGCGGAGTCTTGG-3' and reverse 5'-TCGTTTGTCC GCTCGTTG-3' for Kv4.2 (97 bp in length; Genbank No. NM_031730); forward 5'-CGTCTTTGCCACTGTGATGT-3' and reverse 5'-TCGGCACCATGTCTCCATAC-3' for Kv4.3 (128 bp in length; Genbank No. NM_031739); forward 5'-AGTCCACTGGCGTCTTCA-3' and reverse 5'-CGGACTT CTCATGGTTCACAC-3' for GAPDH (132 bp in length). All assays were performed in triplicate and repeated three times, and the threshold cycle (Ct) was calculated. The relative mRNA expression level normalized by the GAPDH mRNA level was then determined using the $2^{-} \Delta \Delta \mathrm{Ct}$ method (29).

\section{Western blot analysis}

Rat heart tissues were homogenized and lysed in a lysis buffer containing the protease inhibitor phenylmethylsulfonyl fluoride (1 mM; Sigma). Protein concentrations were determined using the bicinchoninic acid method (Nanjing KeyGen Biotech Co., Ltd., China). Equal amounts of protein samples were separated by sodium dodecyl sulfate polyacrylamide gel electrophoresis and transferred to polyvinylidene fluoride membranes. After blocking with $5 \%$ fat-free milk, membranes were incubated overnight at $4^{\circ} \mathrm{C}$ with primary antibodies against Kv1.4 (1:300), Kv4.2 (1:300), Kv4.3 (1:200), and beta-actin (1:400; Boster Biotechnology Co., Ltd., China), followed by incubation with horseradish peroxidase-linked secondary antibodies (1:1000; Zhongshan Jin Qiao Biotechnology Co., Ltd., China). Immunoreactive bands were visualized using an enhanced chemiluminescence detection kit (Amersham Biosciences, USA). Signal intensities were quantitated using the Quantity One Software (Bio-Rad, USA). The relative protein level was determined by normalization against betaactin. Experiments were conducted with a single replicate and repeated three times.

\section{Measurements of plasma glucose and FFA}

At the end of the experiment, rat peripheral blood samples were collected before removing the hearts and plasma was immediately separated. Plasma glucose was measured with a glucometer (Johnson \& Johnson, USA) and plasma FFA was determined by a microplate enzymatic assay using a commercially available kit (Jiancheng Bioengineering Institute, China). All assays were performed in triplicate and repeated three times.

\section{Statistical analysis}

Data are reported as means $\pm S D$. Statistical comparison was performed by one-way analysis of variance (ANOVA) and the two-sided Tukey test. $\mathrm{P}<0.05$ was considered to be statistically significant.

\section{Results}

\section{TMZ reduced plasma FFA levels in rats with DM}

After a 4-week treatment with TMZ, plasma FFA and glucose levels were measured in each animal group. As shown in Table 1, rats with induced DM had significantly greater levels of plasma FFA $(P<0.05$, ANOVA and Tukey test; $N=10)$ and glucose $(P<0.05$, ANOVA and Tukey test; $\mathrm{N}=20$ ) than control animals. TMZ treatment reduced, but failed to completely normalize the plasma FFA concentration in diabetic rats $(P<0.05$ relative to control animals). However, the plasma glucose level remained unchanged after TMZ treatment $(19.30 \pm 1.82$ vs $20.05 \pm 2.51 \mathrm{mM}, \mathrm{P}$ $>0.05$ relative to the $\mathrm{DM}$ group).

\section{$\mathrm{TMZ}$ attenuated the reduction of $I_{\text {to }}$ in diabetic rat hearts}

Electrophysiological studies revealed that the amplitude of $I_{\text {to }}$ was significantly decreased in left ventricular myocytes from diabetic rats compared to those isolated from control animals $(6.25 \pm 1.45$ vs $20.72 \pm 2.93 \mathrm{pA} / \mathrm{pF}$ at $+40 \mathrm{mV}, \mathrm{P}<$ 0.05 , ANOVA and Tukey test; $\mathrm{N}=18$ and 20, respectively; Figure 1). The DM-induced $I_{\text {to }}$ reduction was attenuated by TMZ treatment; however, there were still statistically significant differences between the $\mathrm{DM}+\mathrm{TMZ}$ and control groups $(P<0.05)$. 
Table 1. Effect of trimetazidine treatment of diabetic rats on plasma concentrations of free fatty acids and glucose and expression levels of Kv1.4, Kv4.2, and Kv4.3 mRNA in the left ventricular myocardium.

\begin{tabular}{lccc}
\hline & Control & DM & DM+TMZ $^{\text {a }}$ \\
\hline Free fatty acid $(\mu \mathrm{M})$ & $259.44 \pm 40.68$ & $369.15 \pm 49.03^{*}$ & $323.75 \pm 37.44^{* \#}$ \\
Glucose $(\mathrm{mM})$ & $5.50 \pm 0.5$ & $20.05 \pm 2.51^{*}$ & $19.30 \pm 1.82^{*}$ \\
Kv1.4 mRNA & $0.90 \pm 0.21$ & $2.01 \pm 0.44^{*}$ & $1.02 \pm 0.38^{\#}$ \\
Kv4.2 mRNA & $6.65 \pm 0.88$ & $4.42 \pm 0.61^{*}$ & $5.89 \pm 0.52^{\star \#}$ \\
Kv4.3 mRNA & $5.41 \pm 0.70$ & $3.53 \pm 0.50^{*}$ & $4.91 \pm 0.57^{\#}$ \\
\hline
\end{tabular}

Data are reported as means $\pm S D . D M=$ diabetic group; $D M+T M Z=$ diabetic + trimetazidine group. ${ }^{\text {a Animals }}$ in the $\mathrm{DM}+\mathrm{TMZ}$ group received TMZ $\left(60 \mathrm{mg} \cdot \mathrm{kg}^{-1} \cdot\right.$ day $\left.^{-1}\right)$ by gavage for 4 weeks. ${ }^{*} \mathrm{P}<0.05$ compared to control (one-way ANOVA and Tukey test); $\mathrm{P} P<0.05$ compared to the DM group (one-way ANOVA and Tukey test).

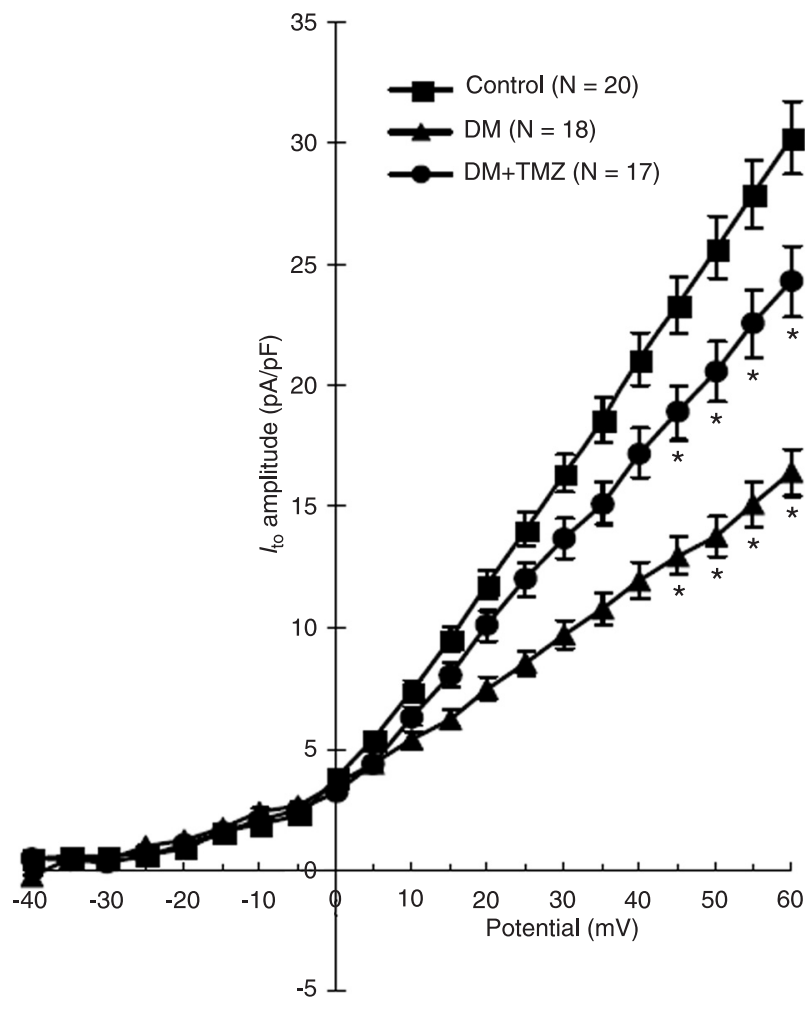

Figure 1. Effect of trimetazidine treatment on $I_{\text {to }}$ current-voltage relationships of diabetic rats. Symbols indicate means \pm SD, and $\mathrm{N}$ indicates the number of myocytes studied. $\mathrm{DM}=$ diabetic group; $\mathrm{DM}+\mathrm{TMZ}=$ diabetic + trimetazidine group; $\mathrm{I}_{\mathrm{to}}=$ outward potassium current. * $\mathrm{P}<0.05$ compared to control (one-way ANOVA and Tukey test).

\section{Decreased expression of Kv4.1 and increased expression of Kv4.2 and Kv4.3 by TMZ}

We next examined the changes in the expression of Kv channel genes in each group. Compared to control animals, diabetic rats showed a >2-fold increase in Kv1.4 mRNA
A
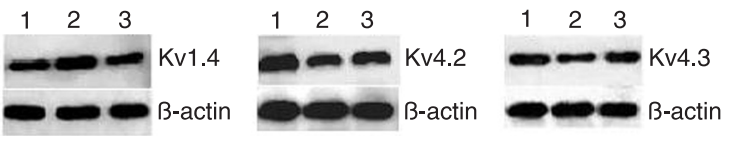

B

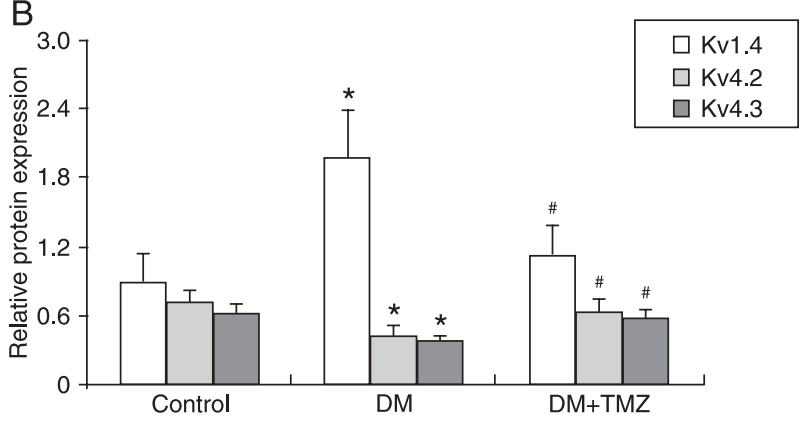

Figure 2. Effect of trimetazidine treatment on the protein levels of $\mathrm{Kv} 1.4, \mathrm{Kv} 4.2$, and $\mathrm{Kv} 4.3$ in the left ventricular myocardium of diabetic rats. $A$, Representative Western blots for each group. Lane 1 = control group; lane 2 = diabetic (DM) group; lane 3 $=$ diabetic + trimetazidine $(\mathrm{DM}+\mathrm{TMZ})$ group. $\beta$-actin was used as loading control. $B$, Bar graph depicting densitometric quantification (means \pm SD) of Western blots for each group. The relative protein level was determined by normalization against that of $\beta$-actin. ${ }^{*} P<0.05$ compared to control (one-way ANOVA and Tukey test); ${ }^{\#} \mathrm{P}<0.05$ compared to the DM group (one-way ANOVA and Tukey test).

levels ( $P<0.05$, ANOVA and Tukey test; $N=10$ ) and a concomitant reduction in mRNA abundance of Kv4.2 $(\mathrm{P}<$ 0.05, ANOVA and Tukey test; $N=10)$ and Kv4.3 $(P<0.05$, ANOVA and Tukey test; $N=10$; Table 1). Similar findings were observed at the protein level (Figure 2), although the extent of these changes varied. The DM-associated alterations in the Kv channel gene expression were almost completely normalized by $\mathrm{TMZ}$ treatment. There was no significant difference in the expression levels of Kv1.4 and Kv4.3 between the control and DM+TMZ groups ( $P>0.05$; Table 1 and Figure 2). 


\section{Discussion}

Using a rat model of type $1 \mathrm{DM}$, we showed that DM was associated with reduction of $I_{\text {to }}$ amplitude in the left ventricular myocardium, coupled with elevated plasma contents of FFA. A 4-week treatment with TMZ resulted in a partial reversal of these metabolic and ionic changes in diabetic rats. Examination of the expression of the $\mathrm{Kv}$ channel genes revealed that DM triggered a shift from fastrecovering Kv4.2/Kv4.3 channels to the slow-recovering

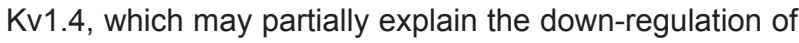
$I_{\text {to }}$ amplitude. Interestingly, TMZ treatment increased the amount of Kv4.2 and Kv4.3 and decreased the expression of $\mathrm{Kv} 1.4$, thus contributing to the up-regulation of $I_{\text {to }}$. These results indicate a protective role for TMZ in DM-associated pathological remodeling of ventricular $I_{\text {to }}$.

Cardiovascular complications, including vascular injuries and myocardial dysfunction, are the primary cause of mortality in patients with DM $(2,3,5,6)$. There are distinct alterations in the electrophysiological properties of the myocardium in diabetic hearts (17). The prolongation of the QT interval, as the most prominent electrophysiological change $(12,13)$, is associated with a high risk of fatal arrhythmias and sudden death in diabetic subjects. The underlying mechanisms of QT abnormalities in diabetic hearts remain poorly understood. The findings in failing hearts suggest that reduced repolarizing currents including $I_{\text {to }}$ are implicated in the pathogenesis of acquired QT prolongation (30). Indeed, previous studies (16-18) and our present results indicate that myocytes isolated from diabetic hearts show a reduction in $I_{\text {to }}$ currents. Changes in the expression of $\mathrm{Kv}$ channel genes have been suggested to underlie the $I_{\text {to }}$ remodeling. Targeted deletion of Kv4.2 in mice results in elimination of the $I_{\text {to,f }}(31)$. Reductions in $\mathrm{Kv} 4.2$ and Kv4.3 amounts have been linked consistently to the diminished $I_{\text {to }}$ densities observed in cardiac hypertrophy (32). Earlier studies $(33,34)$ have documented that ventricular myocytes from diabetic hearts exhibit a decreased level of Kv4.3 and an increased expression of Kv1.4. Our present data confirm the DM-associated changes in the $\mathrm{Kv}$ gene expression profile, i.e., an increase of the Kv1.4 content and a decrease of the contents of both Kv4.2 and Kv4.3. These findings provide a molecular basis for the down-regulation of $I_{\text {to }}$ in diabetic hearts.

There is growing evidence for the link between metabolic changes and cardiac $I_{\text {to }}$ remodeling (35-37). Verkerk et al. (35) reported that inhibition of cell metabolism, induced by hypoxia or by addition of 2,4-dinitrophenol, led to an almost complete inhibition of transient outward current in cardiac myocytes. Similarly, inhibition of metabolism, using 2-deoxyD-glucose to block glycolysis with or without the addition of cyanide to block oxidative phosphorylation, abolished the $I_{\text {to }}$ of rat atrial myocytes (36). Rozanski et al. (37) showed that treatment with exogenous dichloroacetate or pyruvate, both activators of pyruvate dehydrogenase, reversed the reduced $I_{\text {to }}$ in myocytes from infarcted hearts. It is well accepted that DM dramatically alters cardiac substrate metabolism, resulting in augmented FFA and decreased glucose consumption $(21,22)$. This alteration in metabolism is believed to contribute to cardiac dysfunction: high FFA uptake and metabolism not only result in accumulation of FFA intermediates and triglycerides but also in an increased oxygen demand and generation of reactive oxygen species, leading to cardiac damage (38). Normalization of energy metabolism in diabetic hearts is capable of reversing the impaired cardiac function (39). The abnormal accumulation of FFA and their metabolites may have deleterious effects on electrical remodeling in diabetic hearts. Indeed, it has been documented that amphiphilic fatty acid metabolites can reduce $I_{\text {to }}$ in rat ventricular myocytes (20). Long-term fish oil supplementation was found to induce cardiac electrical remodeling by changing channel protein expression in the rabbit model (40). However, there is no direct evidence for the causal relationship between FFA accumulation and cardiac $I_{\text {to }}$ reduction in DM. In addition to FFA elevation, the $I_{\text {to }}$ changes in diabetic hearts may be associated with depressed glucose metabolism, since agents such as insulin, dichloroacetate, and L-carnitine that increase glucose utilization can normalize $I_{\text {to }}$ density within a short period of time (16).

TMZ has multiple metabolic and vascular effects that make it attractive for treatment of cardiovascular diseases (25). The central activity of TMZ is to block fatty acid oxidation, which is likely to be mediated by inhibition of mitochondrial long-chain 3-KAT (24). As a consequence of the TMZ-induced reduction of fatty acid oxidation in the heart, glucose oxidation is stimulated, thus improving cardiac efficiency and function (26). In support of the modulating effects on energy metabolism, the present data revealed that $\mathrm{TMZ}$ selectively decreased plasma FFA concentration in rats with induced DM and did not change plasma glucose levels. However, in patients with type $2 \mathrm{DM}$ and ischemic cardiomyopathy, TMZ failed to alter the basal level of FFA (25). This discrepancy may reflect a context-dependent modulation of FFA levels by TMZ. Accompanying the reduction of plasma FFA, TMZ resulted in augmented $I_{\text {to }}$ in ventricular myocytes. The beneficial effects of $T M Z$ on electrical remodeling may be explained by the altered expression profile of the Kv gene, switching from Kv4.1 to Kv4.2 and $\mathrm{Kv4}$.3. To the best of our knowledge, this is the first report of modulation of $\mathrm{Kv}$ gene expression by $\mathrm{TMZ}$ treatment. The protein levels of the Kv genes varied consistently with their mRNA abundance, suggesting that the regulation of Kv genes occurred primarily at the transcriptional level. However, the exact regulatory mechanisms remain to be clarified. Due to lack of a non-diabetic group treated with $\mathrm{TMZ}$, it is still uncertain whether the effect of TMZ on $I_{\text {to }}$ remodeling is specific for diabetic hearts. Additionally, it is necessary to check whether TMZ had a similar effect on $I_{\text {to }}$ in the setting of type $2 \mathrm{DM}$. 
Our results demonstrate that $\mathrm{TMZ}$ treatment reverses the increased plasma FFA levels and the reduced $I_{\text {to }}$ in left ventricular myocytes of rats with STZ-induced type 1 $\mathrm{DM}$. The modulation of $\mathrm{Kv}$ gene expression is likely to be implicated in the TMZ-induced $I_{\text {to }}$ changes. These findings warrant further evaluation of the relationship between the metabolic effects of TMZ and cardiac electrical remodeling in DM.

\section{References}

1. Wild S, Roglic G, Green A, Sicree R, King H. Global prevalence of diabetes: estimates for the year 2000 and projections for 2030. Diabetes Care 2004; 27: 1047-1053.

2. Mazzone T, Chait A, Plutzky J. Cardiovascular disease risk in type 2 diabetes mellitus: insights from mechanistic studies. Lancet 2008; 371: 1800-1809.

3. Madonna R, De Caterina R. Cellular and molecular mechanisms of vascular injury in diabetes - part I: pathways of vascular disease in diabetes. Vascul Pharmacol 2011; 54: 68-74.

4. van den Oever I, Raterman HG, Nurmohamed MT, Simsek S. Endothelial dysfunction, inflammation, and apoptosis in diabetes mellitus. Mediators Inflamm 2010; 2010: 792393.

5. Wannamethee SG, Shaper AG, Whincup PH, Lennon L, Sat$\operatorname{tar} \mathrm{N}$. Impact of diabetes on cardiovascular disease risk and all-cause mortality in older men: influence of age at onset, diabetes duration, and established and novel risk factors. Arch Intern Med 2011; 171: 404-410.

6. Tarquini R, Lazzeri C, Pala L, Rotella CM, Gensini GF. The diabetic cardiomyopathy. Acta Diabetol 2011; 48: 173-181.

7. Jimenez-Corona A, Nelson RG, Sievers ML, Knowler WC, Hanson RL, Bennett PH. Electrocardiographic abnormalities predict deaths from cardiovascular disease and ischemic heart disease in Pima Indians with type 2 diabetes. Am Heart $J$ 2006; 151: 1080-1086.

8. Stettler C, Bearth A, Allemann S, Zwahlen M, Zanchin L, Deplazes $M$, et al. QTc interval and resting heart rate as long-term predictors of mortality in type 1 and type 2 diabetes mellitus: a 23-year follow-up. Diabetologia 2007; 50: 186-194.

9. Lengyel C, Virag L, Biro T, Jost N, Magyar J, Biliczki P, et al. Diabetes mellitus attenuates the repolarization reserve in mammalian heart. Cardiovasc Res 2007; 73: 512-520.

10. Falcao-Pires I, Hamdani N, Borbely A, Gavina C, Schalkwijk CG, van der Velden J, et al. Diabetes mellitus worsens diastolic left ventricular dysfunction in aortic stenosis through altered myocardial structure and cardiomyocyte stiffness. Circulation 2011; 124: 1151-1159.

11. Sakakibara M, Hirashiki A, Cheng XW, Bando Y, Ohshima $\mathrm{K}$, Okumura T, et al. Association of diabetes mellitus with myocardial collagen accumulation and relaxation impairment in patients with dilated cardiomyopathy. Diabetes Res Clin Pract 2011; 92: 348-355.

12. Rossing $P$, Breum L, Major-Pedersen A, Sato A, Winding $H$, Pietersen A, et al. Prolonged QTc interval predicts mortality in patients with type 1 diabetes mellitus. Diabet Med 2001; 18: $199-205$

13. Veglio M, Chinaglia A, Cavallo-Perin P. QT interval, cardio-

\section{Acknowledgments}

Research supported by the National Natural Science Foundation of China (\#30971213), the Important Project of Chongqing Health Administration (\#20090113), the Doctors Foundation Project of Chongqing Medical University, and the Natural Science Foundation Project of Chongqing (CSTC, \#2008BB5077).

vascular risk factors and risk of death in diabetes. $J$ Endocrinol Invest 2004; 27: 175-181.

14. Nerbonne JM, Kass RS. Molecular physiology of cardiac repolarization. Physiol Rev 2005; 85: 1205-1253.

15. Niwa N, Nerbonne JM. Molecular determinants of cardiac transient outward potassium current $\left(I_{\text {to }}\right)$ expression and regulation. J Mol Cell Cardiol 2010; 48: 12-25.

16. Xu Z, Patel KP, Rozanski GJ. Metabolic basis of decreased transient outward $\mathrm{K}^{+}$current in ventricular myocytes from diabetic rats. Am J Physiol 1996; 271: H2190-H2196.

17. Casis O, Echevarria E. Diabetic cardiomyopathy: electromechanical cellular alterations. Curr Vasc Pharmacol 2004; 2: 237-248.

18. Gallego M, Alday A, Urrutia J, Casis O. Transient outward potassium channel regulation in healthy and diabetic hearts. Can J Physiol Pharmacol 2009; 87: 77-83.

19. Li X, Xu Z, Li S, Rozanski GJ. Redox regulation of $I_{\text {to }}$ remodeling in diabetic rat heart. Am J Physiol Heart Circ Physiol 2005; 288: H1417-H1424.

20. Xu Z, Rozanski GJ. $\mathrm{K}^{+}$current inhibition by amphiphilic fatty acid metabolites in rat ventricular myocytes. Am J Physiol 1998; 275: C1660-C1667.

21. Taegtmeyer H, McNulty P, Young ME. Adaptation and maladaptation of the heart in diabetes: Part I: general concepts. Circulation 2002; 105: 1727-1733.

22. Kota SK, Kota SK, Jammula S, Panda S, Modi KD. Effect of diabetes on alteration of metabolism in cardiac myocytes: therapeutic implications. Diabetes Technol Ther 2011; 13: $1155-1160$

23. Stanley WC, Lopaschuk GD, McCormack JG. Regulation of energy substrate metabolism in the diabetic heart. Cardiovasc Res 1997; 34: 25-33.

24. Kantor PF, Lucien A, Kozak R, Lopaschuk GD. The antianginal drug trimetazidine shifts cardiac energy metabolism from fatty acid oxidation to glucose oxidation by inhibiting mitochondrial long-chain 3-ketoacyl coenzyme A thiolase. Circ Res 2000; 86: 580-588.

25. Monti LD, Setola E, Fragasso G, Camisasca RP, Lucotti $P$, Galluccio E, et al. Metabolic and endothelial effects of trimetazidine on forearm skeletal muscle in patients with type 2 diabetes and ischemic cardiomyopathy. Am J Physiol Endocrinol Metab 2006; 290: E54-E59.

26. Rosano GM, Vitale C, Sposato B, Mercuro G, Fini M. Trimetazidine improves left ventricular function in diabetic patients with coronary artery disease: a double-blind placebo-controlled study. Cardiovasc Diabetol 2003; 2: 16.

27. Morgan PE, Aiello EA, Chiappe de Cingolani GE, Mattiazzi $A R$, Cingolani HE. Chronic administration of nifedipine in- 
duces up-regulation of functional calcium channels in rat myocardium. J Mol Cell Cardiol 1999; 31: 1873-1883.

28. Hamill OP, Marty A, Neher E, Sakmann B, Sigworth FJ. Improved patch-clamp techniques for high-resolution current recording from cells and cell-free membrane patches. Pflugers Arch 1981; 391: 85-100.

29. Livak KJ, Schmittgen TD. Analysis of relative gene expression data using real-time quantitative PCR and the 2(-Delta Delta C(T)) Method. Methods 2001; 25: 402-408.

30. Beuckelmann DJ, Nabauer M, Erdmann E. Alterations of $\mathrm{K}^{+}$currents in isolated human ventricular myocytes from patients with terminal heart failure. Circ Res 1993; 73: 379385.

31. Guo W, Jung WE, Marionneau C, Aimond F, Xu H, Yamada $\mathrm{KA}$, et al. Targeted deletion of Kv4.2 eliminates $I_{\text {to, } f}$ and results in electrical and molecular remodeling, with no evidence of ventricular hypertrophy or myocardial dysfunction. Circ Res 2005; 97: 1342-1350.

32. Kaprielian R, Wickenden AD, Kassiri Z, Parker TG, Liu PP, Backx $\mathrm{PH}$. Relationship between $\mathrm{K}^{+}$channel down-regulation and $\left[\mathrm{Ca}^{2+}\right] \mathrm{i}$ in rat ventricular myocytes following myocardial infarction. J Physiol 1999; 517 (Part 1): 229-245.

33. Qin D, Huang B, Deng L, El-Adawi H, Ganguly K, Sowers $\mathrm{JR}$, et al. Downregulation of $\mathrm{K}\left(^{+}\right)$channel genes expression in type I diabetic cardiomyopathy. Biochem Biophys Res Commun 2001; 283: 549-553.
34. Nishiyama A, Ishii DN, Backx PH, Pulford BE, Birks BR, Tamkun MM. Altered $\mathrm{K}^{+}$channel gene expression in diabetic rat ventricle: isoform switching between $\mathrm{Kv} 4.2$ and $\mathrm{Kv1.4.}$ Am J Physiol Heart Circ Physiol 2001; 281: H1800-H1807.

35. Verkerk AO, Veldkamp MW, van Ginneken AC, Bouman LN. Biphasic response of action potential duration to metabolic inhibition in rabbit and human ventricular myocytes: role of transient outward current and ATP-regulated potassium current. J Mol Cell Cardiol 1996; 28: 2443-2456.

36. Pike GK, Bretag AH, Roberts ML. Modification of the transient outward current of rat atrial myocytes by metabolic inhibition and oxidant stress. J Physiol 1993; 470: 365-382.

37. Rozanski GJ, Xu Z, Zhang K, Patel KP. Altered K ${ }^{+}$current of ventricular myocytes in rats with chronic myocardial infarction. Am J Physiol 1998; 274: H259-H265.

38. An D, Rodrigues $B$. Role of changes in cardiac metabolism in development of diabetic cardiomyopathy. Am J Physiol Heart Circ Physiol 2006; 291: H1489-H1506.

39. Chatham JC, Forder JR. Relationship between cardiac function and substrate oxidation in hearts of diabetic rats. $\mathrm{Am} \mathrm{J}$ Physiol 1997; 273: H52-H58.

40. Xu X, Jiang M, Wang Y, Smith T, Baumgarten CM, Wood MA, et al. Long-term fish oil supplementation induces cardiac electrical remodeling by changing channel protein expression in the rabbit model. PLoS One 2010; 5: e10140. 